Proceeding

\title{
Morphological and chemical findings in drowning: analysis of 10 cases
}

\section{Background and aims}

The determination of chemical substances present in the drowning medium could be a complementary tool in the forensic investigation. ${ }^{1,2}$ Referring to this, both strontium (Sr) and silicon ( $\mathrm{Si}$ ) have proven to be interesting in the diagnosis of drowning (D), in addition to the histological and SEM plankton research in lower airways (Figures 1 \& Figure 2).

Spectrum processing: No peaks omitted

Processing option: Oxygen by stoichiometry (Normalized) Number of iterations $=6$

Standard;

$\mathrm{C} \mathrm{CaCO}_{3}$ 1-Jun-1999 12:00AM

Na Albite 1-Jun-1999 12:00AM Al Al $\mathrm{O}_{3}$ 1-Jun-1999 12:00AM Si $\mathrm{SiO}_{2}$ 1-Jun-1999 12:00AM

$\mathrm{S} \mathrm{FeS}_{2}$ 1-Jun-1999 12:00AM

Ca Wollastonite 1-Jun-1999 12:00 AM Fe Fe 1-Jun-1999 12:00AM

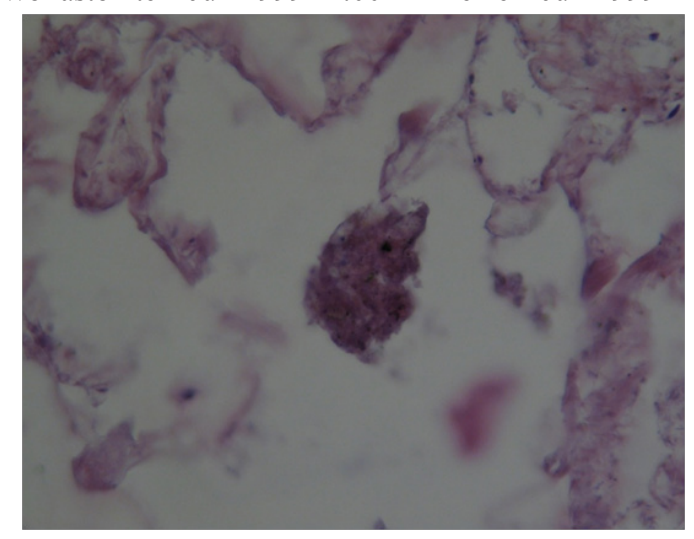

A

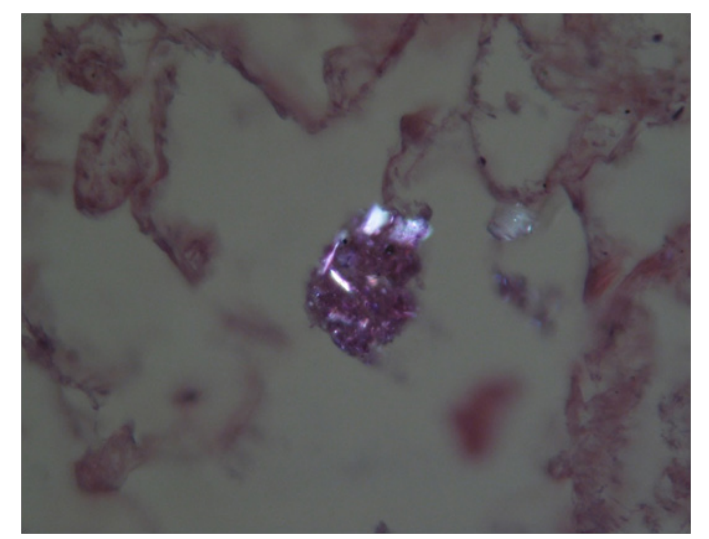

B

Figures I Plankton bolus in the alveolar duct (drowning in freshwater), ordinary (Figure A) and polarized light (Figure B) (EE, 480X).
Volume 6 Issue I - 2018

Pierucci G, Forni D, Lavorato MC, Merlano F

Department of Public Health, Experimental and Forensic Medicine, University of Pavia, Italy

Correspondence: Giovanni Pierucci, Department of Public Health, Experimental and Forensic Medicine, University of Pavia, Italy, Email giovanni.pierucci@unipv.it

Received: November 27, 2017 | Published: January 25, 2018
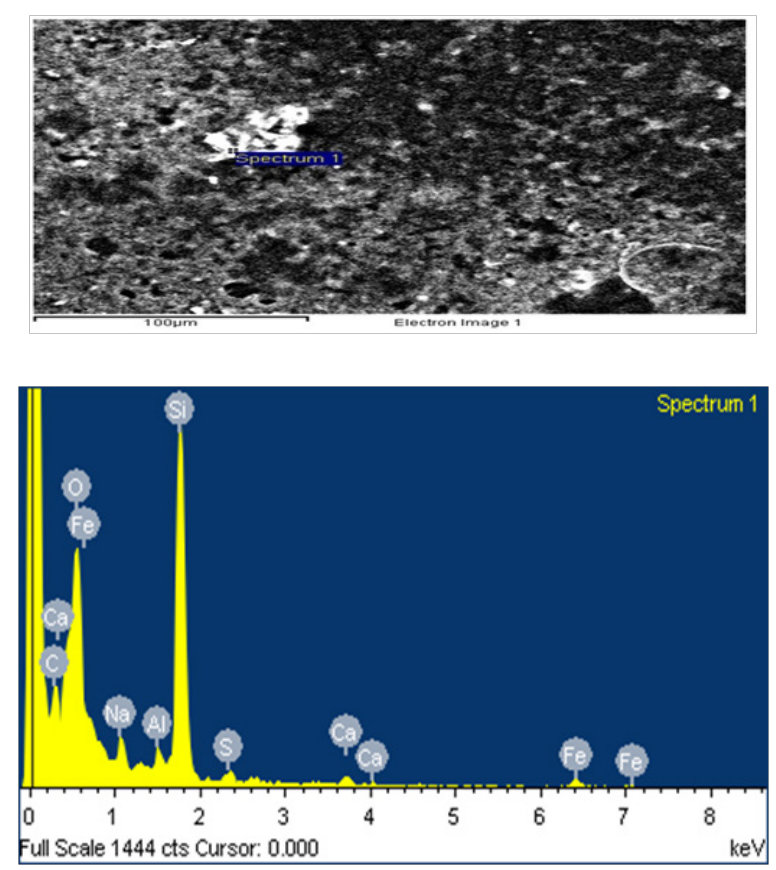

Figure 2 In the upper right, endoalveolar foreign body observed by SEM (case of drowning in freshwater). In the image below, elemental analysis with EDX: more evidence of $\mathrm{Si}$; other organic and inorganic elements.

Table I Chemical findings

\begin{tabular}{lllll}
\hline Element & Weight\% & Atomic\% & Compd\% & Formula \\
\hline $\mathrm{C} \mathrm{K}$ & 17.22 & 23.53 & 63.08 & $\mathrm{CO}_{2}$ \\
$\mathrm{Na} \mathrm{K}$ & 2.21 & 1.58 & 2.98 & $\mathrm{Na}_{2} \mathrm{O}$ \\
$\mathrm{Al} \mathrm{K}$ & 0.73 & 0.44 & 1.38 & $\mathrm{Al}_{2} \mathrm{O}_{3}$ \\
$\mathrm{Si} \mathrm{K}$ & 13.49 & 7.88 & 28.85 & $\mathrm{SiO}_{2}$ \\
$\mathrm{~S} \mathrm{~K}$ & 0.54 & 0.28 & 1.36 & $\mathrm{SO}_{3}$ \\
$\mathrm{Ca} \mathrm{K}$ & 0.55 & 0.23 & 0.77 & $\mathrm{CaO}$ \\
Fe K & 1.23 & 0.36 & 1.59 & $\mathrm{FeO}$ \\
O & 64.03 & 65.7 & & \\
Totals & 100 & & & \\
\hline
\end{tabular}




\section{Materials and methods}

We selected 10 suspected drowning cases, in particular 5 bodies recovered from seawater $\left(\mathrm{S}_{\mathrm{w}}\right)$ and 5 recovered from freshwater $\left(\mathrm{F}_{\mathrm{w}}\right)$. In all cases, the investigation included an anamnestic and circumstantial study, an autopsy and histology, with particular attention to the polarization and fluorescent examination. Within the 5 bodies recovered from the $\mathrm{Sw}$, oligoelements, in particular $\mathrm{Sr}$ and $\mathrm{Si}$ were studied; only $\mathrm{Si}$ was studied in $\mathrm{F}_{\mathrm{w}}$ suspected drowning. This was performed separately for the left (1) and the right (r) ventricles, with special regard to the difference of the concentration of each single oligoelement in both the 1 and $\mathrm{r}$ ventricular blood $\left(\Delta_{l-r}\right)$. Aquatic samples were analyzed in all cases. ${ }^{3}$

\section{Results}

Autopsy: Classic pictures of D. in 9 cases. In 4 cases $\left(\mathrm{S}_{\mathrm{w}}\right)$, the presence of pleural effusion, as well.

Histology: Acute emphysema was the prominent observation; edema and hemorrhages were also present. ${ }^{4}$ In 9cases (Figure 3, Figure 4, Figure $5 \&$ Figure 6), exogenous material in the airways, comprehensive of planktonic boli in the lower branches, clearly demonstrable at polarization microscope (and possibly confirmable at SEM's elemental analysis with EXD). Zoo- and phytoplankton have been better identified in the UV microscope. It is mandatory to differentiate the planktonic material from gastric content, regurgitated and aspirated (Figure $7 \&$ Figure 8).
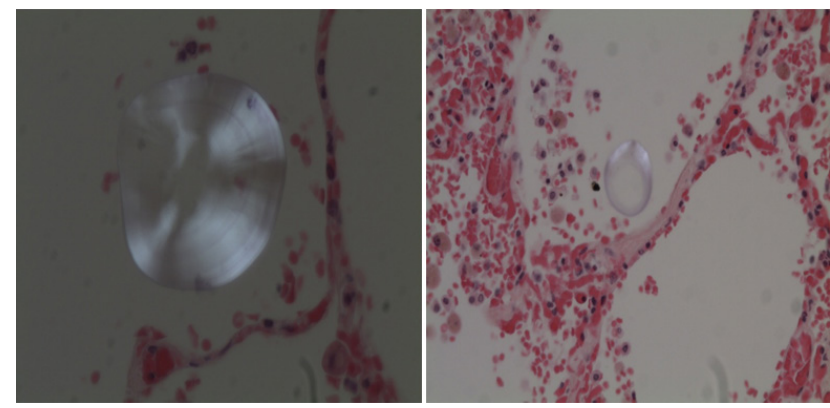

Figure 3 \& Figure 4 Drowning in seawater. Images of endoalveolar zooplankton (protoconch of crustacean) (EE, $480 \mathrm{X}$, polarized light).

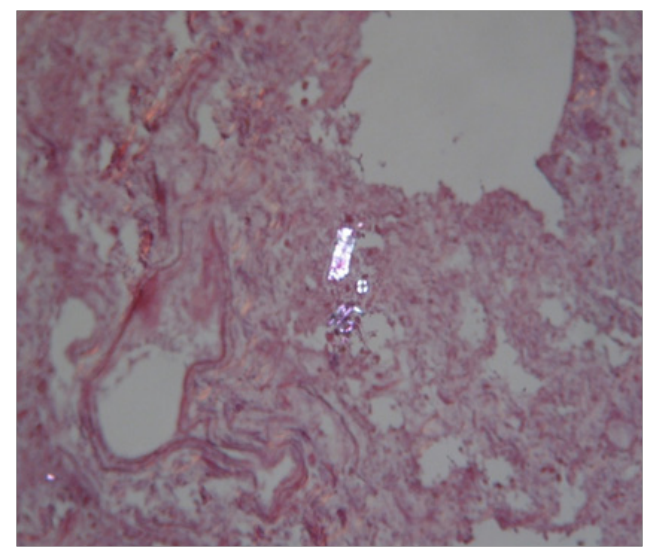

Figure 5 Drowning in freshwater; recovery corpse in the sea after 20days. Endoalveolar phyto- and geoplankton (EE, 240X, polarized light).

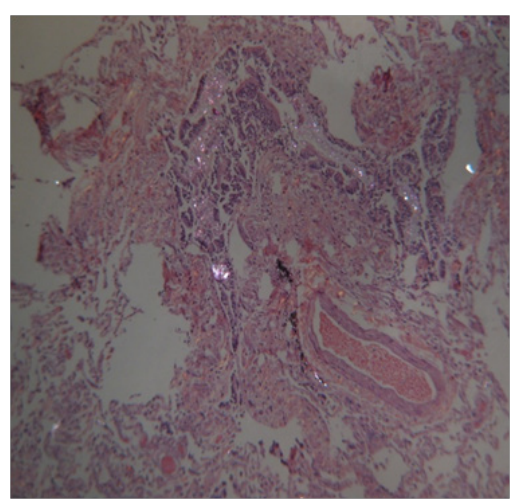

Figure 6 Drowning in freshwater; recovery corpse after few hours. Geo-and phytoplankton in a lower bronchus (EE, I20X, polarized light).

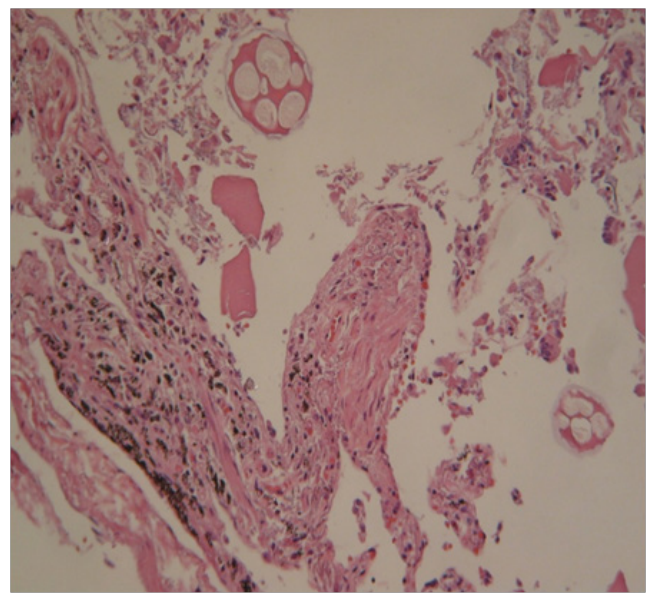

Figure 7 Same case of Figure 7. Fragments of food (cooked meat and tuber cells) in the main stem bronchus (EE, 240X).

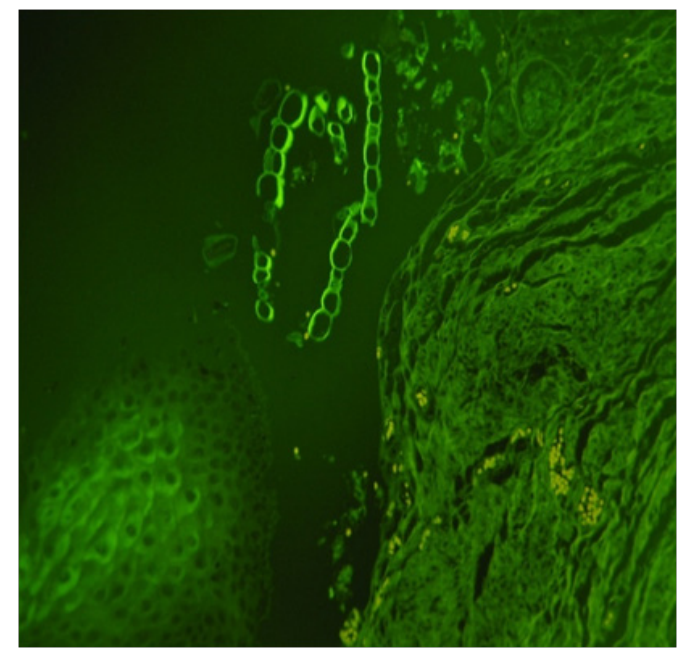

Figure 8 Same case of Figure 7. Plant material identified in the esophageal mucosal laceration (EE, 480X, UV).

Chemical findings: 5 bodies from the $\mathrm{S}_{\mathrm{w}}$ have been investigated. In 4 cases $\left(\Delta_{l-r}\right)$ was significantly positive for $\mathrm{Sr}$ and $\mathrm{Si}$. The only negative for ${ }^{l} \bar{S}_{r}^{r}$ and $\mathrm{Si}$ was a 37 years old subaqueous swimmer and the death was recorded by a camera (Figure 9): histologically, the lungs tested were negative for plankton; disseminated 
myocardiosclerosiswas microscopically identified (sudden death). In $\mathrm{F}_{\mathrm{w}}, \mathrm{Si}\left(\Delta_{l-r}\right)$ was positive in $4 / 5$ cases. $^{5}$

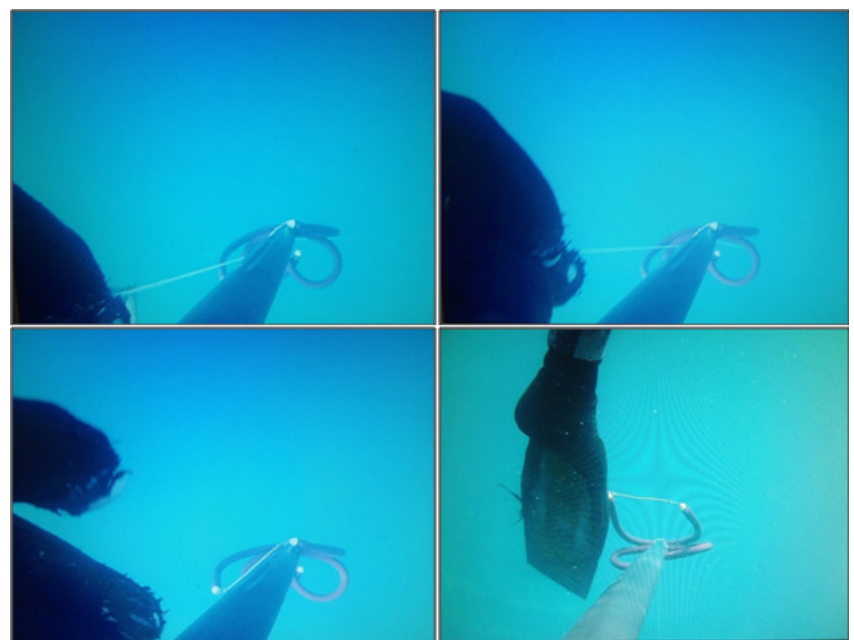

Figure 9 Sudden cardiac death. A 37years old subacquoeous swimmer had plunged in apnea to 40 meters deep. Still images from underwater video (the camera was fixed on the speargun and was recovered on the sea bed): frames $A$ and $B$ (at second 4th and 5 th), the speargun is held by the hand of the swimmer; frame $C$ (at second 7th), the hand leaves the rope; frame $D$ (at second 18th), the speargun moves away from the body and records a right foot flipper.The timing of frames shows the sudden stop of motor functions.

\section{Conclusion}

In order to diagnosis of drowning, our results allow us to propose an investigation protocol, in addition to classical findings. ${ }^{6-13}$

i. Microscopical screening for plankton with polarized light (crystals). Histological research of plankton in the lower bronchi and alveoli;

ii. Research of geoplanckton elements, in particular Si (silicon), with $\mathrm{SEM} / \mathrm{EDX}$.

The determination of oligoelements in the blood of both ventricles: $\left(\Delta_{l-r}\right)$ positive for $\mathrm{Sr}$ e $\mathrm{Si}$ is further support in the diagnosis of $\mathrm{Sw}$ drowning; $\left(\Delta_{l-r}\right)$ positive for $\mathrm{Si}$ in the diagnosis of $\mathrm{F}_{\mathrm{w}}$ drowning.

\section{Acknowledgements}

None.

\section{Conflict of interest}

The author declares no conflict of interest.

\section{References}

1. Perez Carceles, Del Pozo S, Sibon A, et al. Serum biochemical markers in drowning: diagnostic efficacy of strontium and other trace elements. Forensic Sci Int. 2012;214(1-3):159-166.

2. Piette MHA, De Letter EA. Drowning: still a difficult autopsy diagnosis. Forensic Sci Int. 2006;163(1-2):1-9.

3. Azparren JE, Fernandez Rodriguez A, et al. Diagnosing death by drowning in fresh water using blood strontium as an indicator. Forensic Sci Int. 2003;137(1):55-59.

4. Azparren JE, Vallejo G, Reyes E, et al. Study of the diagnostic value of strontium, chloride, haemoglobin and diatoms in immersion cases. Forensic Sci Int. 1998;91(2):123-132.

5. Azparren JE, De la Rosa I, Sancho M. Biventricular measurements of blood strontium in real cases of drowning. Forensic Sci Int. 1994;69:139-148.

6. Piette M, Desmet B, Dams R. Determination of strontium in human whole blood by ICP-AES. Sci Total Environ. 1994;141(1-3):269-273.

7. Chen Y, Alonzo M, Pierucci G. Ricerche istologiche e microanalitiche sul materiale planctonico nei polmoni degli annegati. Zacchia. 2001;74(Suppl):177-186.

8. Chen Y, Tajana L, Addante A, et al. Histological and micro-analytic detection of plankton in lung tissue samples from freshwater and seawater drowning. IALM. 2003;3(5):1-23.

9. Maraschi F, Sturini M, Speltini A, et al. Silicon determination in human ventricular whole blood: a possible marker of drowning. Anal Biochem. 2012;426(2):142-146.

10. Canuto G, Migliardi L. Sulla penetrazione in vita e post-mortem del contenuto gastrico. Arch Antr Crim. 1928;48:870-891.

11. Hu SL, Wen JF, Lai WB, et al. Determination of acidresistant silicic particles in lung by micro-XRF and its application in diagnosis of drowning. Fa Yi Xие Za Zhi. 2010;26(4):257-259.

12. Mauriello S, Palmieri L, Arcudi G. La diagnosi di annegamento: un'autopsia ancora problematica. Zacchia. 2013;86:289-316.

13. Pierucci G, Merlano F, Chen Y, et al. Haematic silicon in drowning. $J$ Forensic Leg Med. 2016;39:22-26. 